\title{
3 Here Today, Gone Tomorrow: Open Access, Open Data and Digital Preservation
}

\subsection{Introduction}

The increasing popularity and pervasiveness of open access and open data approaches within contemporary society continues to have a significant impact on the archaeological profession. A primary concern within these discussions has been the movement towards providing unrestricted access to the peer-reviewed textual content produced in the aftermath of archaeological research, particularly content published in scholarly journals, although other forms of written output (monographs, thesis, books, etc.) have become increasingly drawn into the discussion. A more recent refocusing of this debate generally, and increasingly within archaeological discourse, has seen a return to the issue of accessibility of the primary data produced during research in the hope that openness will promote wider discussion and revitalise understanding. Certainly, the increased and unrestricted access promised by a more open approach to archaeological data is likely to change the nature of archaeological discourse and to facilitate new interpretations of the past. At the same time, the effects of access to the grey data produced during fieldwork within commercial archaeology, although less well understood, could have huge benefits both intellectually and economically. Discussions have suggested that in order to deal with the increasing quantities of open data generated during fieldwork and research the profession will need to develop infrastructures to deal with both the dissemination and preservation of this data (Kintigh, 2006; Snow et al., 2006). It is our intention here to suggest that these two outcomes need not be mutually exclusive; that digital archives and repositories can take a leading role in both the maintenance of access and in the curation of datasets. The experiences of the UK based Archaeology Data Service (ADS) are brought into focus as an instance where both these outcomes have been successfully achieved. Discussions of the work of the ADS have often focused on its role in the preservation of data, but it also taken a leading role as a data broker, aggregator and distributor. It is hoped that a better understanding of the sharing of archaeological data over the longue durèe will help us understand contemporary concerns. In focusing on the work of the ADS we contend that when promoting open data a hybrid approach to dissemination and preservation has the greatest potential to succeed.

Ray Moore: Archaeological Data Service, York, UK

Julian Richards: Archaeological Data Service, York, UK 


\subsection{Sharing Data: The 'Traditional' Treatment of Archaeological Data}

The destructive nature of many forms of archaeological investigation has compelled researchers to make considerable efforts, both legally and ethically, to preserve and disseminate their results. The principal outcome of this research continues to be textbased publication; whether the monograph, book, journal or grey literature report. Yet at the same time archaeological investigations generate significant quantities of primary data which are not easily reproduced or disseminated using traditional media. Data sharing has often been difficult for technical reasons and while paper has proved convenient for the distribution of the textual outputs of archaeological research, it has never been an efficient medium for the dissemination of complex datasets (Jeffrey, 2012). As early as 1975, a review by the Ancient Monuments Board for England concluded that "publication in printed form of all the details of a large modern excavation is no longer practicable" (Frere, 1975, p. 2). This unsustainability led to a 'publication crisis' within British archaeology as the profession struggled to deal with the quantity and scale of the outputs produced by archaeological fieldwork (Richards, 2002). Solutions typically involved limiting the print-based publication, with increased emphasis placed on the archiving of associated data (Frere, 1975; Cunliffe, 1983; Carver et al., 1992). In providing an answer to the crisis in publication, solutions often did so at the expense of accessibility of the data produced during archaeological fieldwork. A working group, created by the Council for British Archaeology and the Department the Environment, attempted to address the accessibility issue by promoting microfiche as an alternative to print (Cunliffe, 1983), but this solution never gained popular acceptance (Richards, 2002; Jones et al., 2001). Unfortunately, "technology lagged behind and lacked the means of providing access to an archive with links between it and the summary publication" (Richards, 2002, p. 356). The increased pervasiveness of digital technology, and the growing popularity of the web, marked a significant sea-change in the landscape opening new avenues for the sharing, collaboration, and analysis of archaeological data. The Publication of Archaeological Projects (PUNS) report, commissioned by the Council for British Archaeology, took a user-driven perspective in examining the use of publications and the data within the profession (Jones et al., 2001). It concluded that:

\footnotetext{
"While print remains favoured, it is clearly no longer the only or even main medium for dissemination. The point has been reached, indeed, at which 'publication' and 'dissemination' must be seen as different things. As a means of giving access to archives or disseminating material that would otherwise be relegated to grey literature, the advantages of the Internet are immense, and increasingly accepted" (Jones et al., 2001, p. 69-70).
}

The PUNS report promoted a 'layered' approach to the publication and dissemination of archaeological research; an approach that takes advantage of the benefits of tex- 
tual and digital technologies and where the traditional narrative can give contextual information and meaning to the archaeological data ${ }^{1}$. Since PUNS there have been no further reviews of publication policy, and its recommendations are still valid, although implementation has been slow. There have been a number of experiments in alternative forms of online and mulit-layered publication, including Scottish Archaeological Internet Reports (Society of Antiquaries of Scotland, 2013) and the LEAP project (Richards et al., 2011). Similarly, Takeda et al. (2013) promote a 'rich interactive framework' which incorporates supplementary information to support journal based publication.

This volume itself demonstrates a growing awareness of the issues associated with openness within archaeological discourse, whilst the recent dedication of an entire volume of World Archaeology, one of the discipline's premier and mainstream journals, to the subject of 'open archaeology' attests to its pervasiveness and entrance into the mainstream (Lake, 2012). At the same time the broad subject matter of these works attests to the innate complexity of the open movement within archaeology; with concepts like open access, open source, open software, open standards, open archaeology etc. already firmly entrenched in the vernacular and increasingly implicated in archaeological practice ${ }^{2}$.

Within archaeology the debate on openness has typically focused on 'open access' publication, and have been particularly focused on its impacts on the 'traditional' outputs of research and grey literature (Lake, 2012). Yet, as the benefits of openness within archaeological publication have been recognised, its expansion to the structured data produced during archaeological research and fieldwork seems logical. The development of so-called 'open data' has, and will continue to have a significant impact on the development of the profession. However, what do we mean by open data? Open data can be broadly defined as, "data that can be freely used, reused and redistributed by anyone - subject only, at most, to the requirement to attribute and share-alike” (Open Knowledge Foundation, n.d.). More specifically it can be defined according to three concepts:

1. Technical openness: data should be made available in widely used, nonproprietary formats that can be used across multiple computing and software platforms.

2. Legal openness: data must be free of encumbering intellectual property restrictions.

3. Access: datasets must be made available freely and, unless there are overriding

1 The implications of this 'linked' approach to the textual and digital outputs of archaeological research will be discussed below.

2 It would be redundant to rehearse the discussions articulated by others in defining the nuances of open archaeology consequently we would refer those seeking a wider understanding of the concept to the other papers in this work and the World Archaeology volume on the subject (Lake, 2012). 
privacy or security needs, data releases need to be both comprehensive and sufficiently documented to enable reuse (Kansa, 2012, p. 506).

For many Open Data is often equated with Linked Open Data and attempts to develop a linked data cloud of open data sets, in which key concepts are each linked to other online sources, in fulfilment of Berners Lee's original vision of a semantic web of machine-readable data (Binding, 2010; Wright, 2011; Isaksen, 2011; Tudhope, Binding, Jeffrey, May and Vlachidis, 2011; Tudhope, May, Binding and Vlachidis, 2011). However, in this paper we are concerned with open data more broadly. In fact the concept of open access to scientific data is not a new one, and long pre-dates the Internet. Indeed, it was first institutionally established in preparation for the International Geophysical Year of 1957-8. The International Council of Scientific Unions established several World Data Centers to minimize the risk of data loss and to maximize data accessibility, further recommending in 1955 that data be made available in machine-readable form. In 2004, the OECD (Organisation for Economic Co-operation and Development) Science Ministers ruled that all publicly funded archive data should be made publicly available.

The European Commission has outlined a 'digital agenda for Europe’ which seeks to promote open data for publicly funded research (2011). Similarly the UK Government has advocated 'a culture of openness' which contends that "access to data is fundamental if researchers are to reproduce and thereby verify results that are reported in the literature" (House of Commons, Department for Business Innovation and Skills, 2012). Endorsing the findings of the Finch report (2012), the UK Government has promoted greater accessibility for research data and grey literature through subject and institutional repositories (House of Commons, Department for Business Innovation and Skills 2012, p. 4; Finch 2012). The government 'Open Data White Paper' "sets out clearly how the UK will continue to unlock and seize the benefits of data sharing" by enhancing access to data and safeguarding it from potential misuse (UK Government Cabinet Office, 2013). In light of these developments research councils, funding agencies and higher education institutions have outlined commitments to open data (Research Councils UK, 2013). The implications of these statements are currently being worked out through the policies and procedures of individual councils, with the Engineering and Physical Sciences Research Council (EPSRC) taking one of the strongest positions to date, namely that research organisations are expected to publish online appropriately structured metadata describing the research data they hold, normally within 12 months of the data being generated, and for the data themselves to be made available without restriction for a minimum of 10 years. Although no additional funding has been made available to support data archives or institutional repositories, research organisations in receipt of EPSRC funding are expected to have a roadmap in place by May 2012 for compliance with the EPSRC policy framework on research data by May 2015. 
The international Open Data Movement has recently received two further boosts. On 13 June 2013 the European Parliament ratified new rules on Open Data, and specifically included cultural heritage data held by public archives museums and galleries. Less than a week later, on 18 June 2013, the Open Data Charter was unveiled at the G8 Summit at Loch Erne, in Northern Ireland. It recognises "a new era in which people can use open data to generate insights, ideas, and services to create a better world for all” (UK Government Cabinet Office, 2013). The G8 Charter establishes 5 principles: (1) that data should be open by default; (2) that steps should be taken to increase the quality, quantity and reuse of data that is released; (3) that it should be usable by all; (4) that releasing data should improve governance; and (5) that releasing data should increase innovation.

Within archaeology we have long recognised the benefits and potential impact that the sharing and reuse of data can bring. Yet, as Kansa observes

“...these barriers show growing cracks as current norms of closed access and data withholding research in archaeology become increasingly untenable and new modes of understanding and communicating the past take root” (Kansa, 2012, p. 499).

Nonetheless, the benefits of increased accessibility, and the messages of open access and open data, are especially poignant for archaeology, given the primary and unrepeatable status of most data sets. Indeed, within

“... a discipline that relies upon destructive research methods, lack of information sharing not only inhibits scholarship, but also represents a tragic loss of irreplaceable cultural and historical knowledge. The discipline urgently requires a more professional approach if researchers are to make credible and replicable knowledge claims and act as better stewards of cultural heritage" (Kansa and Kansa, 2013, p. 88).

As a profession archaeologists have sometimes been reluctant to share their primary research data with others. For some this is attributed to the technical barriers associated with providing access to data (Condron et al., 1999; Kansa and Kansa, 2013) or more practical restrictions on the dissemination of data imposed by publishers or data providers. Yet by far the greatest hurdle to overcome is conceptual; while Pratt has observed that "archaeologists are eager to find ways to publish these data sets" (Pratt, 2013, p. 101), some remain unconvinced about the benefits that open data promotes. Others may be reluctant to expose perceived deficiencies in primary data recording to the critical scrutiny of their peers, or may believe that there is a risk that their data will be published by others before they have the opportunity to do it themselves. An awareness of the academic, symbolic and economic 'capital' of archaeological data streams has hindered the sharing of data (Porter, 2013); whilst potential misuse and misappropriation of data have always been concerns. For Kansa "the discipline should not continue to tolerate the personal, self-aggrandizing appropriation of cultural heritage 
that comes with data hoarding", indeed data withholding "represents a clear threat to preserving the archaeological record” (Kansa, 2012, p. 507).

Such cultural reluctance is not new to archaeology; yet these issues have not precluded the sharing of data in the past, but have simply constrained the scale of dissemination. Within the current climate with disparate groups and communities conducting related research; where the scale of research and the data produced has increased exponentially, such an approach is unsustainable. Open data offers researchers a mechanism to improve disciplinary interaction and, as a consequence, enhance research. The unrestricted accessibility presented by open data also presents archaeology with opportunities to use, and reuse data. Offering the potential for the 'remixing' of archaeological data and its application in new and innovate ways that will enhance understanding the past. The use of text mining and natural language processing within the Archaeotools project, for example illustrates how the application of new analytical techniques to archaeological data can lead to enhanced understandings (Richards et al., 2011). Such re-use may also provide unexpected dividends in the form of re-use of data of research questions that were not envisaged at the outset. In the case of Archaeotools for instance, it became apparent that the application of techniques of information extraction to historic journal runs (in this case the Proceedings of the Society of Antiquaries of Scotland) not only provided a means of automated indexing, but also allowed us to trace the development of controlled vocabularies in archaeology (Bateman and Jeffrey, 2011).

Archaeologists have always been mindful of the need for transparency and repeatability within our negotiations with the past; driven, in part, by a concern over the historical misappropriation of previous generations Trigger (1989); Jones et al. (2001). Increased accessibility has the potential to allow others to test the validity of our interpretations; allowing them to examine and reanalyse the original data. As Lake contends these "[o]pen approaches to knowledge have the potential to bolster scientific rigour by increasing transparency" (Kansa, 2012, p. 473). At the same time this transparency can serve to illustrate the professionalism of data creators by highlighting good research practice (Kansa, 2012).

As ever increasing quantities of open data are released onto the web, concerns have been expressed over the quality of the data. While there are data creators producing well-formed data accompanied by the appropriate metadata, there are large quantities accompanied with only minimal or no documentation. The development of data content, documentation and ontology standards within archaeology has facilitated the creation of 'good', well documented data; data with the highest potential for use and reuse (Richards, 2009; Mitcham et al., 2010). Yet, much is still down to individuals, communities and those institutions hosting data to ensure that these, or similar, standards are adhered to and enforced. Many of these standards are already deeply engrained in archaeological practice. The Guides to Good Practice, created by the ADS and Digital Antiquity have become pivotal to the profession, providing assistance with the ever increasing diversity of data types and formats (Mitcham et al., 
$2010)^{3}$. At the same time quality assurance of digital resources has become necessary, encouraging data creators to document data appropriately. The Journal of Open Archaeology Data (JOAD) ${ }^{4}$ and Internet Archaeology (reference forthcoming) each promote good practice through the production of peer-reviewed data papers which "ensure that the associated data are professionally archived, preserved, and openly available. Equally importantly, the data and the papers are citable, and reuse is tracked" (Journal of Open Archaeology Data, n.d.). Whilst there is certainly a place for such formal appraisals of data, we should not underrate the abilities of data users themselves to make assessments of data quality. The simple fact of the matter is that good data will continue to be used, whilst poor data will not.

\subsection{Accessing Data: The Case of the Archaeology Data Service}

Founded in 1996 the Archaeology Data Service (ADS) was established as one of five disciplinary data centres, under the auspices of Arts and Humanities Data Service (AHDS), to provide specialist advice and expertise during the lifecycle of digital data from its creation, through to its preservation, and onward to its potential reuse. At the same time an awareness of the need for subject specific expertise to assess the research value and successfully validate digital assets and documentation was recognised. From the outset the

“...specific brief of the ADS [was] to collect, describe, catalogue, preserve, and provide user support for the re-use of digital data generated in the course of archaeological research by British archaeologists, wherever they are working” (Richards, 1997, p. 1058).

In doing so it provides support for research, learning and teaching within the archaeological sector, through the provision of freely available, high quality and dependable digital resources. This is achieved through the preservation and dissemination of digital data over the long term; an action that has allowed data creators and users to plan not only for preservation, but also use and reuse of digital assets. Throughout its existence the ADS has maintained a broad collections policy that covers all the archaeology of the British Isles, and all areas of the globe where British archaeologists undertake research. It maintains data resources from chronologically, thematically and geographically disparate areas, so much so that now maintains over 1100 digital collections created by individuals, projects and organisations working within both academic and commercial sectors. Of course this is not to say that all digital data should be preserved. As one of the authors has previously suggested the costs of archiving

3 The Guides to Good Practice, developed by the Archaeology Data Service and Digital Antiquity, http://guides.archaeologydataservice.ac.uk/, accessed 30 August 2013.

4 JOAD - http://openarchaeologydata.metajnl.com/, accessed 30 August 2013. 
mean that "it is important to establish the reuse potential of any data set before expending resources on its preservation" (Richards, 2002, p. 347); a belief that continues to underpin the ADS philosophy (Richards, 1997). As a result the focus of the ADS has always been in preserving quality, well documented datasets that show the greatest potential for reuse.

Throughout its history a principal focus of the ADS has been the preservation of data created during archaeological fieldwork and research. As noted above the majority of UK funding bodies now recommend, and increasingly require, that digital data produced during research should be preserved. At the same time the landscape has changed significantly in recent years as museums and 'traditional' physical archives, many of which lack the necessary digital expertise, progressively compel those working in commercial archaeology to deposit the digital outputs of fieldwork into a mandated digital archive. In both instances the ADS has taken a role in the preservation of archaeological data. Many will be familiar with its work in traditional academic research environments, but it also works with partners within the commercial sector. Acting as a data broker, it has assisted in the creation of OASIS, an online form used throughout the profession to record the outcomes of archaeological fieldwork (Hardman, 2009) ${ }^{5}$. The OASIS system has been enhanced by a facility that allows users to upload the reports produced as a consequence of these activities. These outputs are preserved and, perhaps more significantly, disseminated through the ADS' Grey Literature Library ${ }^{6}$. This library now provides direct access to some 20,000 unpublished fieldwork reports, produced by over 140 contracting units working within Britain; and has become an important research tool in its own right (Fulford and Holbrook, 2011).

While much discussion has focused on the work of the ADS in preserving the outputs of archaeological research its role as a data disseminator has received much less attention. It has offered free access to its collections and the data therein, a policy developed long before the concepts of open access had been rigorously defined. The terms of use developed by the ADS provide access to data through a "nonexclusive, non-transferable licence" with the depositor (Archaeological Data Service, n.d.); which means:

"Anyone is permitted to use data held by the ADS so long as it is for research or educational purposes, and these are defined quite broadly as purposes intended to develop knowledge and where the research output is itself destined for the public domain. Therefore reuse of data held by ADS by commercial contractors is not prevented so long as publication of their work is not limited by issues of client confidentiality” (Richards, 2002, p. 349).

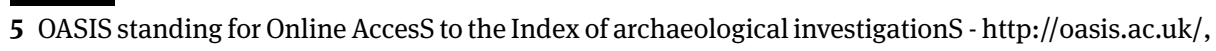
accessed 21 September 2014.

6 The Grey Literature Library - http://archaeologydataservice.ac.uk/archives/view/greylit/, accessed 21 September 2014. 
In seeking to protect the rights of the depositor the ADS conditions of use are therefore broadly equivalent to a CC-BY-NC licence. Indeed, the terms of use state that the ADS "seeks to protect the intellectual property rights and copyright of the originators of data where that can reasonably be achieved" through a common access agreement (Archaeological Data Service, n.d.). Encouraging them to be "fair and reasonable in their use of the data supplied" (Archaeological Data Service, n.d.). At the same time those depositing data are expected to sign a deposit licence that declares their copyright and ownership to all the data within the collection (Richards, 2002); an action that serves to project the rights of other data creators. This policy has obvious drawbacks, indeed the ADS has even refused deposits where the ownership is obscure or where it is derived from data streams of other individuals and organisations (Mitcham, n.d.). Therefore the approach taken by the ADS places a much greater emphasis on securing the intellectual property rights of data creators, whereas the onus within a full open data environment is firmly placed on the user. For many these 'restrictions' may seem prohibitive, yet experience suggests this is not the case (Heath, 2010). This is not to say that the ADS insists on a single rights management framework, and when requested data can be disseminated under another form of licence. The Antikythera Survey Project, for example, is disseminated under an open data compliant Creative Commons licence (CC-BY 3.0) (Bevan and Conolly, 2012).

While increased accessibility and reuse has done much to raise awareness of the intrinsic value of research data, official recognition of its importance has served to encourage data creators to share these outcomes. The UK Government, for example, has stated that:

\footnotetext{
"The work of researchers who expend time and effort adding value to their data, to make it usable by others, should be acknowledged as a valuable part of their role. Research funders and publishers should explore how researchers could be encouraged to add this value” (UK Government, 2011).
}

Despite this change in mind-set the data outputs of archaeological research can still be treated with some diffidence; an incongruent outcome of less significance than the final interpretation or synthesis. Costa, et al. propose that in order to overcome this mind-set archaeological data needs to treated as "a more relevant part of the archaeological publication, research, management, curation and policy process, and not merely an afterthought” (Costa et al., Forthcoming; Atici et al., 2013; Pratt, 2013). The solution advocated by many is treat the dissemination of data as a form of publication; one which should employ established practice found within text-based publishing, included citation and editorial control (Kansa et al., 2010; Kansa and Kansa, 2011). This it is believed will instil a sense of familiarity to process of disseminating and citing digital resources. This movement towards, what is termed 'data sharing as publication', is intended make the dissemination of data "a more regular and integral part of professional practice” (Bevan and Conolly, 2012, p. 161). 
To a large extent such 'publication of data' is already part of the ADS workflow. From the outset has endeavoured to promote links between the traditional outputs of research and supporting datasets. The ADS and the e-journal Internet Archaeology have co-published peer-reviewed articles and associated data (Internet Archaeology, n.d.). The award-winning Linking Electronic Archives and Publications (LEAP) project set out explicitly to provide a series of exemplars of linked publications and archives, including the projects of Merv, Silchester, Troodos, and Whittlewood (Richards et al., 2011). Of course this relationship is not exclusive and the ADS has always disseminated data on behalf of other digital and paper based reports and articles. Working with the Council for British Archaeology the ADS distributes digital versions of its research reports and occasional papers, including additional supporting data and other material(for British Archaeology, 2007). The ADSnow has an agreement with Elsevier to provide access to supplementary data supporting articles in the Journal of Archaeological Science. Our ejournal Internet Archaeology has also published articles linked to data sets held in other data archives, including tDAR in the United States (Holmberg, 2010). This linking of content is not restricted to the research environment; within commercial archaeology the ADS disseminate data derived from large-scale infrastructural developments, such as Channel Tunnel Rail Link(Framework Archaeology, 2011a) and Heathrow Terminal 5 (Framework Archaeology, 2011b);bridging the gap between the traditional fieldwork monograph and the supporting digital data. Working with Southampton Arts and Heritage the ADS has also published some 12 discrete excavation archives from the Southampton area, each of which is linked to the grey literature report lodged in the Grey Literature Library ${ }^{7}$.

A more open archaeology and the dissemination of increasing quantities of data will necessitate the development of new techniques and tools to deal with the proper referencing and citation of digital resources; indeed without this there is a very real possibility of becoming 'lost in information' (Huggett, 2012). At the same time a common concern amongst data creators is the lack of accreditation for data. Both concerns could be addressed through improved citation. Traditionally digital resources have utilised the URL to reference digital resources, however, the durability of this method of citation has begun to be questioned (Jeffrey, 2012). A number of schemes have attempted to address this issue; one of these is the DOI system which "allows collections of data or individual data files to be allocated a URL that will not change irrespective of changes to the physical location of the files in question" (Jeffrey, 2012, p. 564). The 'minting' and subsequent management of DOI's is handled by a conglomerate of organisations, working as part of the International DOI Foundation, who guarantee the sustainability of the citation system (Datacite, n.d.). As an adopter of the DOI system the ADS creates persistent identifiers that consistently and accurately reference dig-

7 Part of the Southampton's Designated Archaeology Collections Programme - http: //archaeologydataservice.ac.uk/archives/view/southampton/, accessed 23 August 2013. 
ital objects and collections. This serves to address one the principal concerns of the PUNS report (Jones et al., 2001) by formalising associations between digital resources and printed outputs. An important outcome of the DOI system is that it also allows citations to be tracked, meaning that data creators, users and repositories can track the use and impact of specific data sets or publications (Hole, 2012).

\subsection{Conclusion}

The movement towards open data, and the associated dissemination of ever increasing quantities of data, has the potential to transform archaeology and our understandings of the past. While some contend that "we face the great challenge of bridging two realities - moving from currently entrenched practices to a future of more open and diverse scholarly outputs" (Kansa and Kansa, 2013, p. 103) others have recognised that "many of the wider social, cultural, political and economic issues raised by the various planks of the 'Open' movement are not in themselves new” (Lake, 2012, p. 476). Within the UK the work of the ADS in facilitating access, promoting good practice, endorsing proper citation and encouraging the reuse of research data is making an important contribution towards the Open Data movement. The growing propensity for open data within archaeological discourse will continue to necessitate change and the development of new archiving techniques and workflows, but the experience of the ADS confirms the important role of discipline-based data archives in supporting open access and suggests that the current infrastructure has the innate flexibility to deal with the new demands of a more open archaeology. The pressure from funders requiring research institutions to ensure open access and preservation of data generated by their employees has led to a rapid development of institutional repositories, but whilst the majority provide excellent self-archiving and pre-print repositories in support of open access publication, they also recognise that the long term curation of primary and specialist research data requires them to work with discipline-based data archives. Indeed, the exchange of metadata allows institutions to maintain an institutional view of datasets produced by their employees, and to satisfy audit purposes, whilst sub-contracting long term curation of specialist data sets to other facilities (Rumsey and Jefferies, 2013). A 2011 report commissioned by the Research Information Network and the JISC from Talis concluded that national data centres have an important role to play in terms of providing a focus for data access, overcoming the potential fragmentation of multiple institutional repositories with a focus on short term curation rather than access, and that there was considerable additional valueadded from a discipline-based view (JISC, 2011). In 2013, another JISC-funded survey was undertaken by Neil Beagrie and John Houghton into the Impact and Value of the ADS (Beagrie and Houghton, 2013). Adopting techniques for measuring the economic value of non-costed services, Beagrie and Houghton concluded that over a period of 30 years, every £1 invested in ADS, would yield an economic return to the UK economy of 
up to $£ 8.30$. Whilst the value of Open Data should not be seen in economic terms alone, and we would argue that there are strong societal benefits from providing open public access to our shared cultural heritage, the economic argument in favour of Open Data is a useful one. Hopefully it will ensure the current political pressures in favour of Open Data will continue, and that the archaeological profession will continue to benefit from them.

\section{Bibliography}

Archaeological Data Service (n.d.).

URL: http://archaeologydataservice.ac.uk

Atici, L., Kansa, S. W., Lev-Tov, J. and Kansa, E. C. (2013), 'Other people’s data: A demonstration of the imperative of publishing primary data', Journal of Archaeological Method and Theory 20(4), 663-681.

Bateman, J. and Jeffrey, S. (2011), 'What matters about the monument: reconstructing historical classification', Internet Archaeology 29.

Beagrie, N. and Houghton, J. (2013), 'The value and impact of the archaeology data service. a study and methods for enhancing sustainability', Archaeology Data Service .

Bevan, A. and Conolly, J. (2012), 'The antikythera survey project [data-set]'. URL: http://archaeologydataservice.ac.uk/archives/view/antikythera_ahrc_2012/

Binding, C. (2010), Implementing archaeological time periods using CIDOC CRM and SKOS, in 'The Semantic Web: Research and Applications', Springer, pp. 273-287.

Carver, M., Chapman, H., Cunliffe, B., Hassall, T., Hebditch, M., Lawson, A., Longworth, I., Morris, R., Phillipson, D., Schofield, J. and Others (1992), 'Archaeological publication, archives and collections. towards a national policy', London: Society of Antiquaries. Printed as a supplement to British Archaeological News 7(2).

Condron, F., Richards, J., Robinson, D. and Wise, A. (1999), Strategies for digital data: findings and recommendations from digital data in archaeology: a survey of user needs, Archaeology Data Service, University of York. URL: http://ads.ahds.ac.uk/project/strategies/

Costa, S., Beck, A., Bevan, A. and Ogden, J. (Forthcoming), 'Defining and advocating open data in archaeology'.

Cunliffe, B. (1983), The publication of archaeological excavations: The report of a joint working party of the Council for British Archaeology and the Department of the Environment, Joint Working Party.

Datacite (n.d.). URL: http://www.datacite.org/

Finch, J. (2012), 'Accessibility, sustainability, excellence: how to expand access to research publications', Report of the Working Group on Expanding Access to Published Research Findings .

URL: http://www.researchinfonet.org/publish/finch/

for British Archaeology, C. (2007), 'Cba research reports'.

Framework Archaeology (2011a), 'Channel tunnel rail link section 1 [data-set]'. URL: http://archaeologydataservice.ac.uk/archives/view/t5_framework_2011/

Framework Archaeology (2011b), 'Framework archaeology heathrow terminal [data-set]'. URL: http://archaeologydataservice.ac.uk/archives/view/ctrl/

Frere, S. (1975), Principles of Publication in Rescue Archaeology: Report by a Working Party of the 
Ancient Monuments Board for England, Committee for Rescue Archaeology, Department of the Environment.

Fulford, M. and Holbrook, N. (2011), 'Assessing the contribution of commercial archaeology to the study of the roman period in england, 1990-2004', The Antiquaries Journal 91, 323-345.

Hardman, C. (2009), 'The online access to the index of archaeological investigations (OASIS) project: facilitating access to archaeological grey literature in england and scotland', The Grey Journal 5(2), 76-82.

Heath, S. (2010), Diversity and reuse of digital resources for ancient Mediterranean material culture, Farnham, UK: Ashgate, pp. 35-52.

Hole, B. (2012), A Call for Open Scholarship in Archaeology, Archetype.

Holmberg, K. (2010), 'Placing immateriality: Situating the material of highland chiriquî', Internet Archaeology 28.

House of Commons, Department for Business Innovation and Skills (2012), Letter to Dame Janet Finch on the Government Response to the Finch Group Report: "Accessibility, sustainability, excellence: how to expand access to research publications", London.

Huggett, J. (2012), 'Lost in information? ways of knowing and modes of representation in earchaeology', World Archaeology 44(4), 538-552.

Internet Archaeology (n.d.). URL: http://intarch.ac.uk/

Isaksen, L. (2011), Archaeology and the semantic web, PhD thesis, University of Southampton. Jeffrey, S. (2012), 'A new digital dark age? collaborative web tools, social media and long-term preservation', World Archaeology 44(4), 553-570.

JISC, R. I. N. . (2011), Data centres: their use, value and impact, London: The Research Information Network.

Jones, S., MacSween, A., Jeffrey, S., Morris, R. and Heyworth, M. (2001), 'From the ground up: the publication of archaeological projects, a user needs survey'.

Journal of Open Archaeology Data (n.d.), 'JOAD'. URL: http://openarchaeologydata.metajnl.com/

Kansa, E. (2012), 'Openness and archaeology's information ecosystem', World Archaeology 44(4), 498-520.

Kansa, E. C. and Kansa, S. (2011), Toward a do-it-yourself cyberinfrastructure: open data, incentives, and reducing costs and complexities of data sharing, Cotsen Institute of Archaeology Press Los Angeles, CA, pp. 57-91.

Kansa, E. C., Kansa, S., Burton, M. M. and Stankowski, C. (2010), 'Googling the grey: Open data, web services, and semantics', Archaeologies 6(2), 301-326.

Kansa, E. C. and Kansa, S. W. (2013), 'Additional thoughts on sustaining and promoting open data in archaeology', Journal of Eastern Mediterranean Archaeology and Heritage Studies 1(1), 102-103.

Kintigh, K. (2006), 'The promise and challenge of archaeological data integration', American Antiquity pp. 567-578.

Lake, M. (2012), 'Open archaeology', World Archaeology 44(4), 471-478.

Mitcham, J. (n.d.), Preservation of Digital Objects at the Archaeology Data Service, Portsmouth: The University of Portsmouth, pp. 76-85.

Mitcham, J., Niven, K. and Richards, J. (2010), Archiving archaeology: Introducing the guides to good practice.

Open Knowledge Foundation (n.d.), 'Open data - an introduction'.

URL: http://okfn.org/opendata/

Porter, B. W. (2013), 'Sharing data is hard!-but worth it', Journal of Eastern Mediterranean Archaeology and Heritage Studies 1(1), 100-101.

Pratt, D. (2013), 'Not an either/or proposition: combining interpretive and data publication', Journal 
of Eastern Mediterranean Archaeology and Heritage Studies 1(1), 101-102.

Research Councils UK (2013), RCUK Policy on Open Access and Supporting Guidance, London.

Richards, J. D. (1997), 'Preservation and re-use of digital data: the role of the archaeology data service', Antiquity 71(274), 1057-1059.

Richards, J. D. (2002), 'Digital preservation and access', European journal of archaeology 5(3), 343366.

Richards, J. D. (2009), 'From anarchy to good practice: the evolution of standards in archaeological computing', Archeologia e Calcolatori pp. 27-35.

Richards, J., Jeffrey, S., Waller, S., Ciravegna, F., Chapman, S. and Zhang, Z. (2011), The Archaeology Data Service and the Archaeotools project: faceted classification and natural language processing, Cotsen Institute of Archaeology, Los Angeles, CA, pp. 31-56.

Rumsey, S. and Jefferies, N. (2013), 'Datafinder: A research data catalogue for oxford', Ariadne 71.

Snow, D., Gahegan, M., Giles, C., Hirth, K., Milner, G., Mitra, P. and Wang, J. (2006), 'Information science. cybertools and archaeology.', Science 311(5763), 958.

Takeda, K., Earl, G., Frey, J., Keay, S. and Wade, A. (2013), 'Enhancing research publications using rich interactive narratives', Philosophical Transactions of the Royal Society A: Mathematical, Physical and Engineering Sciences 371(1983).

Trigger, B. G. (1989), A history of archaeological thought, Cambridge University Press.

Tudhope, D., Binding, C., Jeffrey, S., May, K. and Vlachidis, A. (2011), 'A STELLAR role for knowledge organization systems in digital archaeology', Bulletin of the American Society for Information Science and Technology 37(4), 15-18.

Tudhope, D., May, K., Binding, C. and Vlachidis, A. (2011), 'Connecting archaeological data and grey literature via semantic cross search', Internet Archaeology 30.

UK Government (2011), 'Science and technology committee - eighth report'. URL: http://www.publications.parliament.uk/pa/cm201012/cmselect/cmsctech/856/85602.htm UK Government Cabinet Office (2013), 'G8 open data charter and technical annex'. URL: https://www.gov.uk/government/publications/open-data-charter/g8-open-data-charterand-technical-annex

Wright, H. (2011), Seeing Triple: Archaeology, Field Drawing and the Semantic Web, PhD thesis. 